Article

\title{
A Method for Downscaling FengYun-3B Soil Moisture Based on Apparent Thermal Inertia
}

\author{
Chengyun Song ${ }^{1,2}$ and Li Jia ${ }^{1,3, *}$ \\ 1 State Key Laboratory of Remote Sensing Science, Institute of Remote Sensing and Digital Earth, \\ Chinese Academy of Sciences, Beijing 100101, China; schyun007@163.com \\ 2 School of Geodesy and Geomatics, Anhui University of Science \& Technique, Huainan 232001, China \\ 3 Joint Center for Global Change Studies, Beijing 100875, China \\ * Correspondence author: jiali@radi.ac.cn; Tel.: +86-10-6480-7982
}

Academic Editors: Zhongbo Su, Yijian Zeng, Zoltan Vekerdy, Gabriel Senay, Richard Müller and Prasad S. Thenkabail

Received: 29 March 2016; Accepted: 9 August 2016; Published: 26 August 2016

\begin{abstract}
FengYun-3B (FY-3B) soil moisture product, retrieved from passive microwave brightness temperature data based on the Qp model, has rarely been applied at the catchment and region scale. One of the reasons for this is its coarse spatial resolution $(25-\mathrm{km})$. The study in this paper presented a new method to obtain a high spatial resolution soil moisture product by downscaling FY-3B soil moisture product from $25-\mathrm{km}$ to $1-\mathrm{km}$ spatial resolution using the theory of Apparent Thermal Inertia (ATI) under bare surface or sparse vegetation covered land surface. The relationship between soil moisture and ATI was first constructed, and the coefficients were obtained directly from 25-km FY-3B soil moisture product and ATI derived from MODIS data, which is different from previous studies often assuming the same set of coefficients applicable at different spatial resolutions. The method was applied to Naqu area on the Tibetan Plateau to obtain the downscaled $1-\mathrm{km}$ resolution soil moisture product, the latter was validated using ground measurements collected from Soil Moisture/Temperature Monitoring Network on the central Tibetan Plateau (TP-STMNS) in 2012. The downscaled soil moisture showed promising results with a coefficient of determination $R^{2}$ higher than 0.45 and a root mean-square error (RMSE) less than $0.11 \mathrm{~m}^{3} / \mathrm{m}^{3}$ when comparing with the ground measurements at 5 sites out of the 9 selected sites. It was found that the accuracy of downscaled soil moisture was largely influenced by the accuracy of the FY-3B soil moisture product. The proposed method could be applied for both bare soil surface and sparsely vegetated surface.
\end{abstract}

Keywords: soil moisture; downscaling; Apparent Thermal Inertia; FY-3B

\section{Introduction}

Soil moisture is one of the important variables in hydrological and meteorological models, and has been used in numerous applications, such as weather forecasting, drought monitoring and flood area mapping, among others [1,2]. Passive microwave remote sensing is suitable for monitoring soil moisture for its high sensitivity to soil moisture, ability to penetrate to vegetation canopy and less influence by clouds [3,4]. The Microwave Radiation Imager (MWRI) onboard the Fengyun-3B (FY-3B) satellite is a passive microwave sensor, which provides brightness temperature observations at five frequencies from $10.7 \mathrm{GHz}$ to $89 \mathrm{GHz}$. FY-3B soil moisture product is retrieved using $10.7 \mathrm{GHz}$ brightness temperature based on the Qp model [5]. Similar to many other microwave sensors such as the Sensor Microwave/Imager (SSM/I), Advanced Microwave Scanning Radiometer (AMSR-E) onboard NASA's Earth Observing System and Soil Moisture and Ocean Salinity (SMOS) [6,7], the spatial resolution of MWRI onboard FY-3B is from $18 \mathrm{~km}$ to $85 \mathrm{~km}$ and the resolution of its soil moisture product is about $25 \mathrm{~km}$ accordingly. NASA Soil Moisture Active Passive mission (SMAP) was designed 
to provide high resolution soil moisture retrieved jointly with passive and active data [8]. However, the radar sensor has stopped working since 7 July 2015. The improved soil moisture products are combined by other soil moisture products $[9,10]$, and the spatial resolution is still at about $25 \mathrm{~km}$-resolution. Since soil moisture at higher spatial resolutions, e.g., 1-10 km, is often needed for many applications [11,12], it is therefore urgent to develop algorithms to obtain such fine resolution data.

Many studies have concentrated on downscaling soil moisture using high resolution optical/thermal spectral and radar data [13-16]. For example, the "universal triangle" method has been used to downscale low resolution soil moisture in regions covered by low vegetation [14]. As the method was developed based on the feature space between land surface temperature (LST) and vegetation index (VI) over heterogeneous areas, a wide range of both NDVI and surface moisture conditions is usually needed within the study region [13,14]. Another method is the physical and theoretical method based on the relationship between fractional vegetation cover and soil evaporative efficiency, which was used to downscale soil moisture of SMOS data using optical/thermal spectral data [17]. However, soil and vegetation parameters needed in this method are often difficult to obtain at a global scale. The change detection method was proposed to downscale soil moisture retrieved by passive microwave data by using the active microwave data from Synthetic Aperture Radar (SAR) [15,18]. However, the change detection method may cause error accumulation, and long-time SAR data are not available at global scale with sufficient high temporal resolution.

Thermal inertia represents the capability of a material to conduct and store heat, and it is a function of thermal conductivity, bulk density and specific heat capacity of the target. Since the change of soil water content tends to cause the change of thermal conductivity, thermal inertia can be used for soil moisture monitoring [19]. Several parameters, such as bulk density, specific heat capacity and thermal conductivity, are used to calculate thermal inertia. These parameters are often hard to obtain at a regional scale. Alternatively, Apparent Thermal Inertia (ATI) is proposed to replace thermal inertia, and it can be obtained using surface albedo and a night-day land surface temperature pair data that usually can be retrieved from satellite remote sensing observations. ATI can be derived directly with remote sensing data such as those from Moderate Resolution Imaging Spectroradiometer (MODIS), Advanced Very High Resolution Radiometer (AVHRR) and Meteorological Satellite (METEOSAT) data [20-22]. Sensors on sun-synchronous polar orbiting satellites could observe land surface at day and night time, such as the MODIS sensor onboard Aqua and Terra satellites. Van Doninck et al. (2011) used MODIS day and night land surface temperature to determine the full daily land surface temperature cycle and calculate ATI with the MODIS data at 1-km resolution [23].

Former studies on downscaling soil moisture using optical/thermal data were usually conducted under the assumption that the parameters of the model are the same at different spatial scales [13,14]. The model parameters are easily obtained at coarse scale and are directly applied to high resolution data. Such assumption is not always valid if the model parameters are scale dependent. In this paper, a method based on the relationship between soil moisture and ATI is proposed to downscale 25-km FY-3B soil moisture to $1-\mathrm{km}$, in which the model parameters at high resolution are calculated with FY-3B soil moisture at $25-\mathrm{km}$ resolution and ATI derived by MODIS data at 1-km resolution. The downscaled soil moisture is evaluated using ground measurements collected from the northern Tibetan Plateau in the southwest of China. As ATI was considered to be suitable for soil moisture monitoring under bare surface or sparse vegetation covered land surface, e.g., usually when NDVI is lower than 0.4 [24], the algorithm proposed in the current study are more applicable to bare surface or sparse vegetation covered land surface.

\section{Method}

The method of downscaling coarse resolution soil moisture is based on the relationship between land surface soil moisture and ATI. The FY-3B soil moisture can be downscaled from 25-km resolution to $1-\mathrm{km}$ resolution with the ATI, the latter is derived from MODIS land surface temperature and albedo data at $1-\mathrm{km}$ resolution. 
ATI is a simplified formulation of thermal inertia (TI) and can be used to monitor soil moisture conditions based on the same principle as TI. Thermal inertia (TI) is an indicator of the material resistance to changes in temperature and is defined as:

$$
T I=\sqrt{\lambda \rho q}
$$

where $\rho\left(\mathrm{kg} \cdot \mathrm{m}^{-3}\right)$ is the material density, $\lambda\left(\mathrm{W} \cdot \mathrm{m}^{-1} \cdot \mathrm{K}^{-1}\right)$ is the thermal conductivity, $q$ is the specific heat capacity $\left(\mathrm{J} \cdot \mathrm{kg}^{-1} \cdot \mathrm{K}^{-1}\right)$.

The difference of TI among water, dry soils, and rocks makes it possible to monitor soil moisture with TI. The increase of soil moisture will cause the increase of TI and thus the reduction of the diurnal land surface temperature amplitude. However, the definition of TI contains soil thermal conductivity and soil density, which are hard to obtain especially by remote sensing observations at regional scale. Alternatively, ATI is proposed to monitor soil moisture and is defined as:

$$
A T I=C \frac{1-\alpha_{0}}{A}
$$

where $A(\mathrm{~K})$ is the amplitude of diurnal land surface temperature cycle, $\alpha_{0}(-)$ is the surface albedo, $C$ is the solar correction factor depending on location and time.

The diurnal land surface temperature cycle in Equation (2) can be determined with the day and night land surface temperature from Terra/MODIS and Aqua/MODIS data. The method used for ATI calculation in this paper is adapted from the one proposed by Van Doninck et al. [23] with day and night MODIS land surface temperature and 8-day albedo. The details of the calculation of ATI are described in the Appendix A.

Many previous studies have found stable relationship between soil moisture and ATI [23-26]. Logarithmic relationship between soil moisture and ATI was proposed by Notarnicola et al. (2013) [24] and Qin et al. (2013) [27], and can be written as below:

$$
S M_{p}=a_{p} * \ln \left(A T I_{p}+c_{p}\right)+b_{p}
$$

where $S M_{p}$ is soil moisture at scale $p ; a_{p}, b_{p}$ and $c_{p}$ are regression coefficients at the same scale $p$. Once these three coefficients are defined at high spatial resolution, the soil moisture at the same high spatial resolution can then be obtained by Equation (3) providing ATI is available at the same spatial scale. Since soil moisture observations at high spatial resolution are not available for regression using Equation (3), it is necessary to develop an alternative algorithm to calculate the coefficients in Equation (3).

A pixel with low spatial resolution is composed by a number of pixels with finer spatial resolution. A linear mixing model is used to link the land surface soil moisture in a pixel at low spatial resolution $\left(S M_{L}\right)$ to the soil moisture at finer spatial resolution within that low spatial resolution pixel $\left(S M_{H}\right)$ by:

$$
S M_{L}=\frac{1}{N} \sum_{i=1}^{N} S M_{H, i}
$$

where $N$ is the number of the pixels with high spatial resolution within the pixel of low spatial resolution.

Assuming that the relationship in Equation (3) and the coefficients are independent on pixels, the following expression is obtained by combining Equations (3) and (4),

$$
S M_{L}=\frac{1}{N} \sum_{i=1}^{N}\left[a_{H} L N\left(A T I_{H, i}+c_{H}\right)+b_{H}\right]=a_{H} \frac{1}{N} \sum_{i=1}^{N}\left[L N\left(A T I_{H, i}+c_{H}\right)\right]+b_{H}
$$


where the subscript $H$ denotes high spatial resolution, subscript $L$ denotes low spatial resolution, other symbols are the same as those in Equation (3).

It is still hard to obtain the coefficients in Equation (5) even though both soil moisture of low spatial resolution and ATI of high spatial resolution are known. In order to build the relationship between soil moisture and ATI at low spatial resolution, we assume that the Logarithmic relationship between soil moisture and ATI can be written as:

$$
S M_{p}=d_{p} * L N\left(A T I_{p}\right)+g_{p}
$$

where $d_{p}$ and $g_{p}$ are coefficients at scale $p$ respectively.

Combining Equations (4) and (6), the soil moisture of a pixel at low resolution can be given by:

$$
S M_{L}=d_{H} * \frac{1}{N} \sum_{i=1}^{N} L N\left(A T I_{H, i}\right)+g_{H}
$$

where $d_{H}$ and $g_{H}$ are regression coefficients linking the ATI at high spatial resolution to the soil moisture at low spatial resolution, $i$ is the pixel of high resolution within a pixel of low spatial resolution. It is possible to get the coefficients $d_{H}$ and $g_{H}$ with regression algorithm using soil moisture at low spatial resolution and ATI at high spatial resolution in Equation (7). Once the coefficients are known, soil moisture at high spatial resolution can be obtained with Equation (6). We also assume that the relationship and coefficients between soil moisture and ATI are the same in the whole study area for the same date under the condition with bare soil surface or sparsely vegetated surface.

The soil moisture at high spatial resolution is obtained by downscaling the low-resolution soil moisture using the method described above. Soil moisture of a pixel with low spatial resolution is the weighted averages of the soil moisture of pixels with high spatial resolution fallen in each low spatial resolution pixel. However, when the downscaled soil moisture at high spatial resolution $\left(S M_{H D}\right)$ and soil moisture at low spatial resolution are presented in the Equation (4), the two sides of the equation is not usually equal due to the bias in the high spatial resolution soil moisture. The bias can be expressed as Equation (8) at low spatial resolution:

$$
S M_{b i a s}=S M_{L}-\frac{1}{N} \sum_{i=1}^{N} S M_{H D, i}
$$

where $i=1, \ldots, N$ is number of pixels at high spatial resolution within a pixel with low spatial resolution.

In order to remove the bias, the downscaled soil moisture at high resolution is corrected with the bias, and the bias is obtained by resampling the bias at the low resolution with Bilinear Interpolation method.

Since FY-3B Microwave Imager (MWSI) can provide soil moisture at 25-km spatial resolution and ATI can be derived from MODIS data at 1-km spatial resolution, soil moisture at 1-km resolution can then be obtained by downscaling FY-3B soil moisture using ATI derived by MODIS data at 1-km resolution with Equations (6)-(8).

Three steps are implemented to downscale $25-\mathrm{km}$ FY-3B soil moisture to 1-km resolution (see Figure 1 for the flowchart):

Firstly, ATI is derived with MODIS data at 1-km high spatial resolution, and the natural logarithm of 1-km ATI are aggregated to the spatial resolution of FY-3B soil moisture (25-km).

Secondly, the coefficients in Equation (7) are obtained with regression algorithm using 25-km FY-3B soil moisture and the aggregated natural logarithm of ATI from MODIS 1-km data.

Thirdly, the high resolution soil moisture $(1 \mathrm{~km})$ is derived with Equation (6) and the bias in high resolution soil moisture is removed according to Equation (8). 
The spatial distribution of NDVI of the study area on 19 July 2012. The north part of the study area is almost bare soil and partially covered by alpine grass, the south part is typically characterized by alpine grasslands and glaciers. Water bodies are scattered in the study area. The study period is from 1 January 2012 to 31 December 2012.

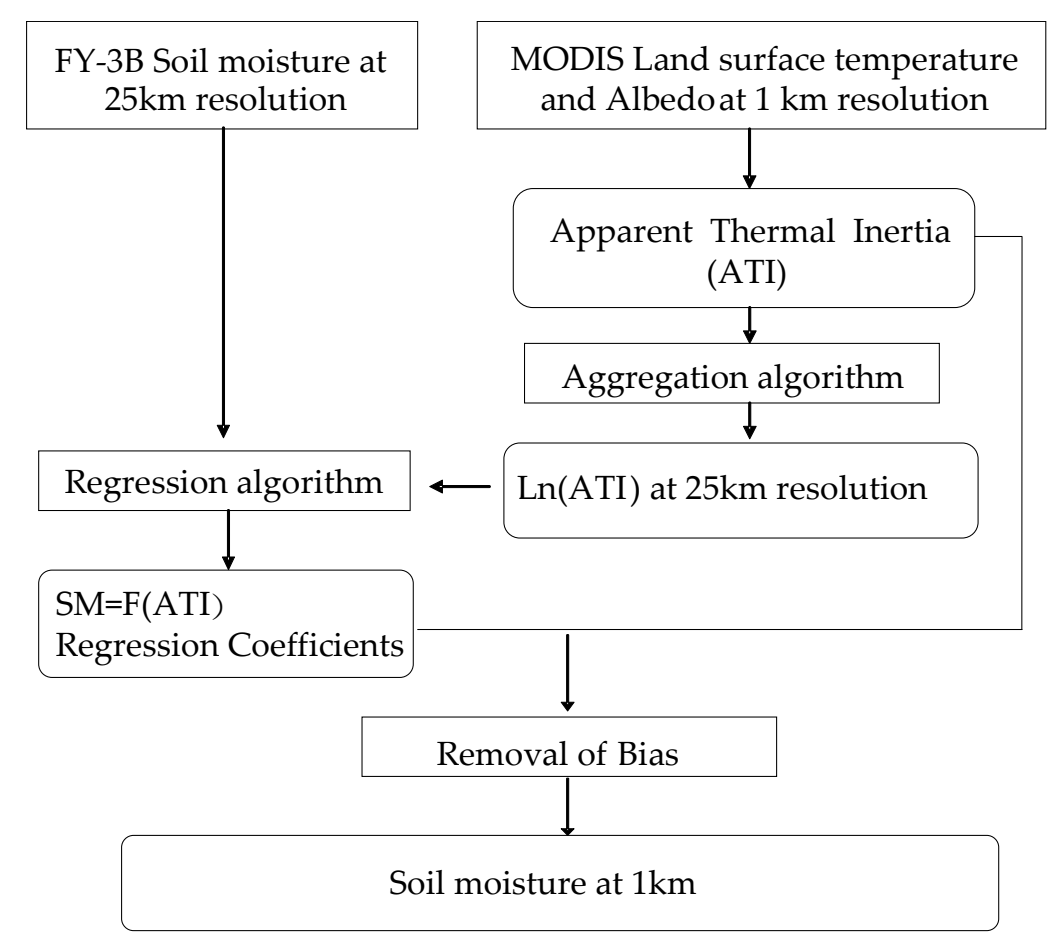

Figure 1. Schematic diagram for downscaling 25-km FY-3B soil moisture to 1-km spatial resolution.

\section{Study Area and Data}

Naqu area, located in the northern Tibetan Plateau (TP) in the southwest of China, was selected as the study area to test the algorithm for soil moisture downscaling. This area is located between $85^{\circ}-95^{\circ} \mathrm{E}$ and $30^{\circ}-38^{\circ} \mathrm{N}$ and the terrain elevation is higher than $4500 \mathrm{~m}$. Figure 2a shows.

(a)

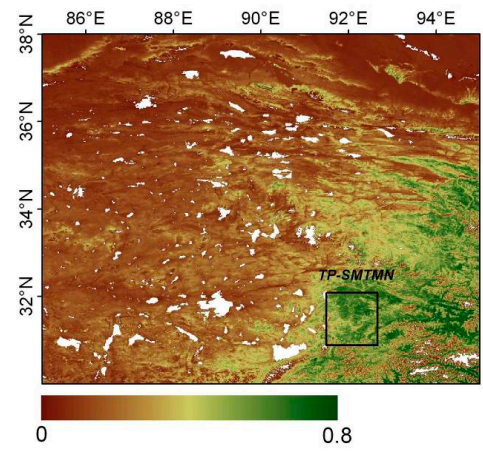

(b)

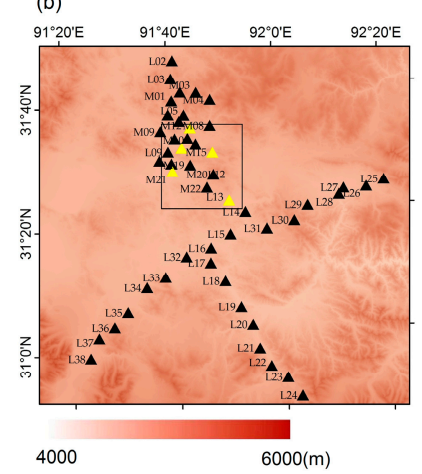

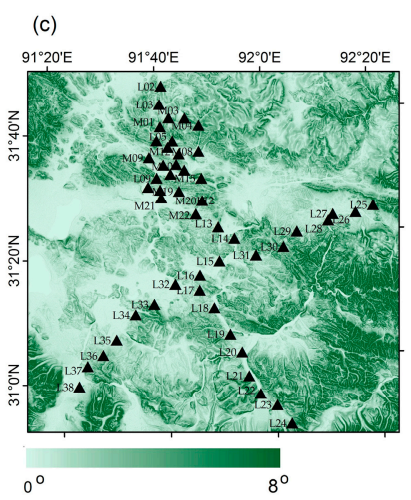

Figure 2. (a) NDVI of the study area on 19 July 2012; (b) Sites and the Digital Elevation Model (DEM) (The black box is the area that covered by one pixel of FY-3B soil moisture image); and (c) the slope of the TP-SMTMN near Naqu on the Tibetan Plateau.

FY-3B soil moisture at 25-km resolution are derived from FY-3B/MWRI $10.7 \mathrm{GHz}$ brightness temperature and downloaded from Fengyun Satellite Data Center [28]. MODIS MOD11A1 and 
MYD11A1 1-km daily land surface temperature and MCD13A2 1-km 8-day albedo were downloaded from the National Snow and Ice Data Center (NSIDC) to calculate ATI [29]. Compared with other soil moisture retrieval algorithms, the algorithm used by FY-3B product reduced the influence of soil roughness by using the double polarization brightness temperature at $10.7 \mathrm{GHz}$ instead of the roughness parameter.

In situ soil moisture data were collected from Soil Moisture/Temperature Monitoring Network on the central TP (TP-SMTMN) which is located in the southeast of the study area [30]. Figure $2 \mathrm{~b}$ is the Digital Elevation Model (DEM) of the ground measurements network. The TP-SMTMN provides observation data of soil moisture and soil temperature at three scales (large, middle and small scale) with spatial extent about 1 degree, 0.3 degrees and 0.1 degrees, respectively. The time interval of observations was $30 \mathrm{~min}$, and the measurements depths are $5 \mathrm{~cm}, 10 \mathrm{~cm}, 20 \mathrm{~cm}$ and $40 \mathrm{~cm}$ respectively. Most of the stations of the network started working since August 2010, and the last six stations were established in June 2012.

As FY-3B soil moisture product will also be evaluated with the ground measurements of soil moisture, the nine sites located within one pixel of FY-3B soil moisture image were used. The 9 sites are shown in the black box in Figure 2b. The DEM and the slope of the TP-SMTMN are shown in Figure 2b,c. Soil moisture measurements at $5 \mathrm{~cm}$ depth at the nine sites from 1 January 2012 to 31 December 2012 were used to evaluate the results.

\section{Results and Discussion}

\subsection{Validation of 25-km Spatial Resolution FY-3B Soil Moisture Product}

Since soil moisture at low spatial resolution is the input of our downscaling method, the FY-3B soil moisture at $25-\mathrm{km}$ spatial resolution is firstly evaluated with ground-measured soil moisture. The average values of the soil moisture measured at the nine experimental sites within the FY-3B pixel is compared with the pixel value of FY-3B soil moisture for the year 2012 (Figure 3).

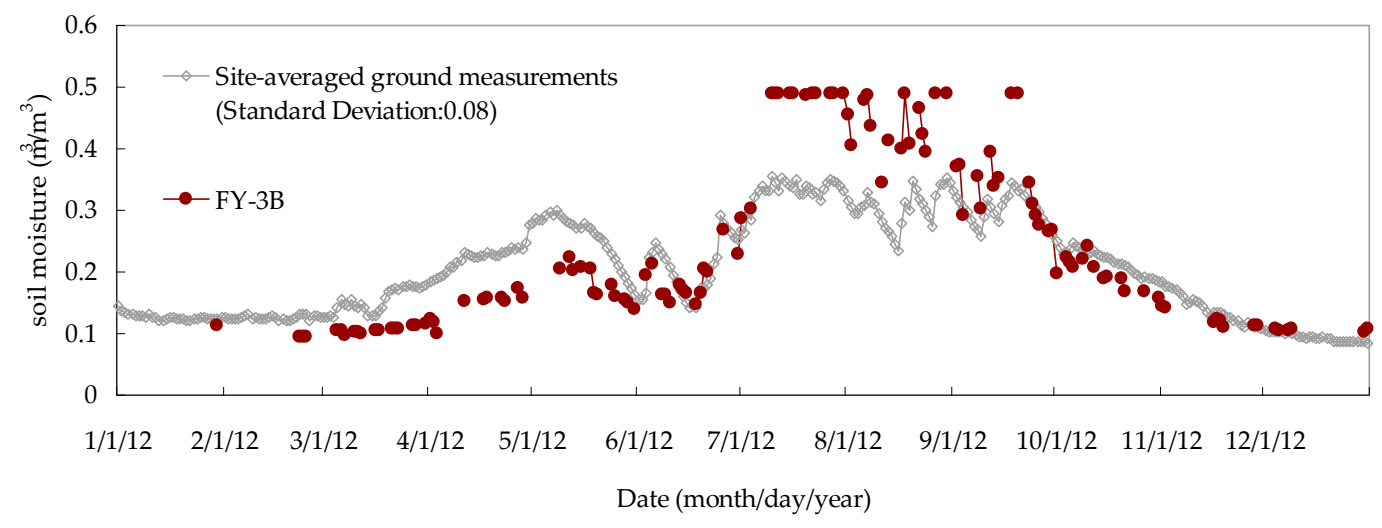

Figure 3. Time series of FY-3B soil moisture at $25-\mathrm{km}$ spatial resolution and site-averaged measurements from the SMTMN on the Tibetan Plateau in 2012.

In general, the temporal pattern of the FY-3B soil moisture time series are similar to ground measurements in the year of 2012. However, FY-3B soil moisture is higher in summer and lower in spring and autumn than the site-averaged soil moisture in 2012. Since soil liquid water was frozen when the temperature was under zero degree in winter period (from November to next January), soil moisture was not retrieved in the FY-3B soil moisture product during this period. The FY-3B soil moisture showed underestimation from March to May of 2012, and overestimation in the monsoon season from mid-July to mid-September of 2012. The land surface layer was undergoing the processes of ice thawing and snow melting from the end of March to May of 2012 which has led to large spatial variation in soil moisture content at land surface in the region. As a consequence, 
the site-averaged measurements of soil moisture may not represent the soil moisture at a scale of $25-\mathrm{km}$ pixel. Overestimation of soil moisture occurred in the monsoon season in 2012 when the soil moisture was close to saturation in most of the monsoon season. When the soil surface was close to saturation soil moisture value approaches to $0.5 \mathrm{~m}^{3} / \mathrm{m}^{3}$, which is the maximum range in the FY-3B soil moisture retrieval algorithm. In addition, the overestimation of vegetation transmissivity in the area covered by the dense vegetation may be another factor that caused the overestimation of soil moisture in FY-3B product.

Figure 4 is the scatter plot of the FY-3B soil moisture product against the site-averaged soil moisture measurements in frozen and unfrozen seasons respectively in 2012. The determinant coefficient $\left(R^{2}\right)$ is 0.77 for the unfrozen season, higher than that in the frozen season $\left(R^{2}\right.$ is 0.3$)$. Root Mean-Square Error (RMSE) in the unfrozen season and the frozen season are $0.087 \mathrm{~m}^{3} / \mathrm{m}^{3}$ and $0.039 \mathrm{~m}^{3} / \mathrm{m}^{3}$, respectively, which correspond to the soil moisture in unfrozen season ranging between $0.14 \mathrm{~m}^{3} / \mathrm{m}^{3}$ and $0.36 \mathrm{~m}^{3} / \mathrm{m}^{3}$ and to the soil moisture in frozen season usually below $0.15 \mathrm{~m}^{3} / \mathrm{m}^{3}$. The larger RMSE is most likely attributed to uncertainties in soil moisture retrieval in summer season when vegetation is dense, this is due to the fact that signals from soil is perturbed by the dense vegetation above it.
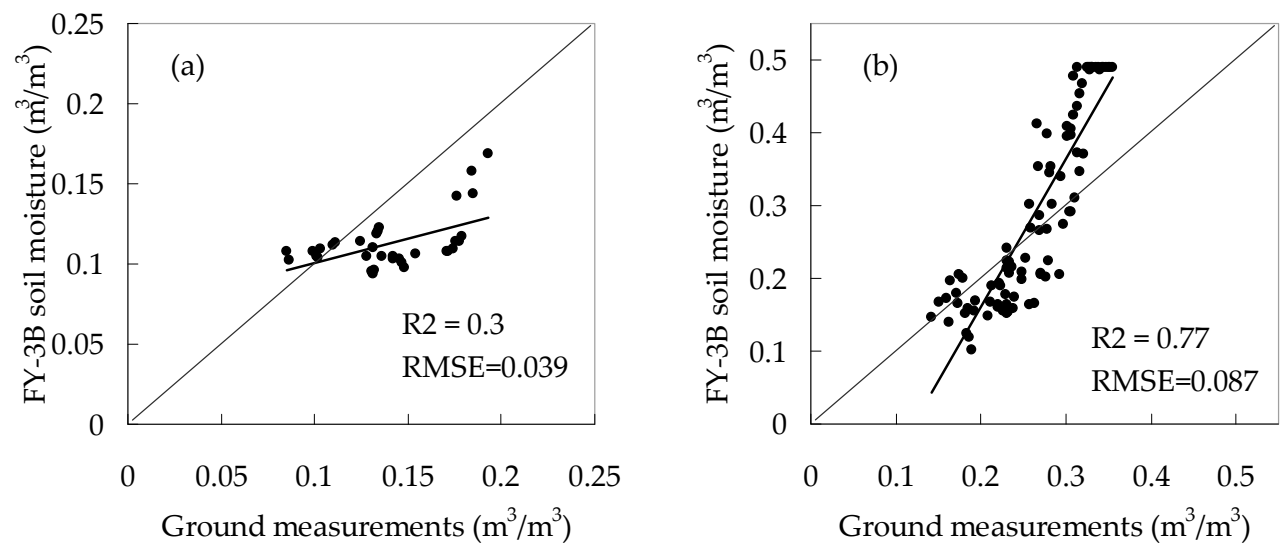

Figure 4. Comparison of FY-3B soil moisture and ground measurements from the SMTMN on the Tibetan Plateau in (a) frozen and (b) unfrozen period in 2012.

\subsection{The Relationship between Soil Moisture and ATI}

The linear-logarithmic relationship between soil moisture and ATI (Equation (6)) is also evaluated using the same ground measurements. Since each site is located in different pixels of 1-km spatial resolution image, ground-measured soil moisture can only be used to represent pixel-retrieved soil moisture if soil moisture is homogeneously distributed in the pixel. Among the nine sites of the SMTMN on the Tibetan Plateau which are used to test FY-3B soil moisture, the five sites (M10, M14, M15, M21 and L13 site) which were located in a relatively flat area with slope less than 6 degrees (see sites symbolized with yellow triangles in Figure $2 b$ ) were selected to evaluate the relationship between surface soil moisture and ATI (Equation (6)). The surface condition within each one of the five sites was relatively homogeneous according to our ground survey. Soil moisture measured at the five sites and ATI of the corresponding pixels derived from MODIS data were collected for regression analysis using Equation (6). In addition, ATI was considered to be suitable for soil moisture monitoring under bare surface or sparse vegetation covered land surface, e.g., when NDVI is lower than 0.4 [26]. Figure 5 shows the regression curves at the five sites in which the green curve is the bulk regression curve of all the five sites. When NDVI was lower than 0.4 , the regression curves at the five sites were quite close to each other with $R^{2}$ all higher than 0.6 , indicating that the logarithmic model seems to be robust. The difference in the regression curves at the five sites is mainly caused by the different vegetation coverage and soil types. In addition, ATI cannot be obtained every day for each pixel due to the influence of clouds on MODIS LST data. This leads to different dates being selected for the 
regression analysis at the five sites, which may also cause the difference of regression curves among the sites. The $R^{2}$ is lower than 0.3 at the five sites when NDVI is higher than 0.4 . The reason is that ATI calculated with MODIS LST and Albedo data cannot reflect soil moisture conditions when vegetation cover is dense. In the further analysis of this study, the downscaling algorithm will only be applied to the conditions when NDVI is lower than 0.4.
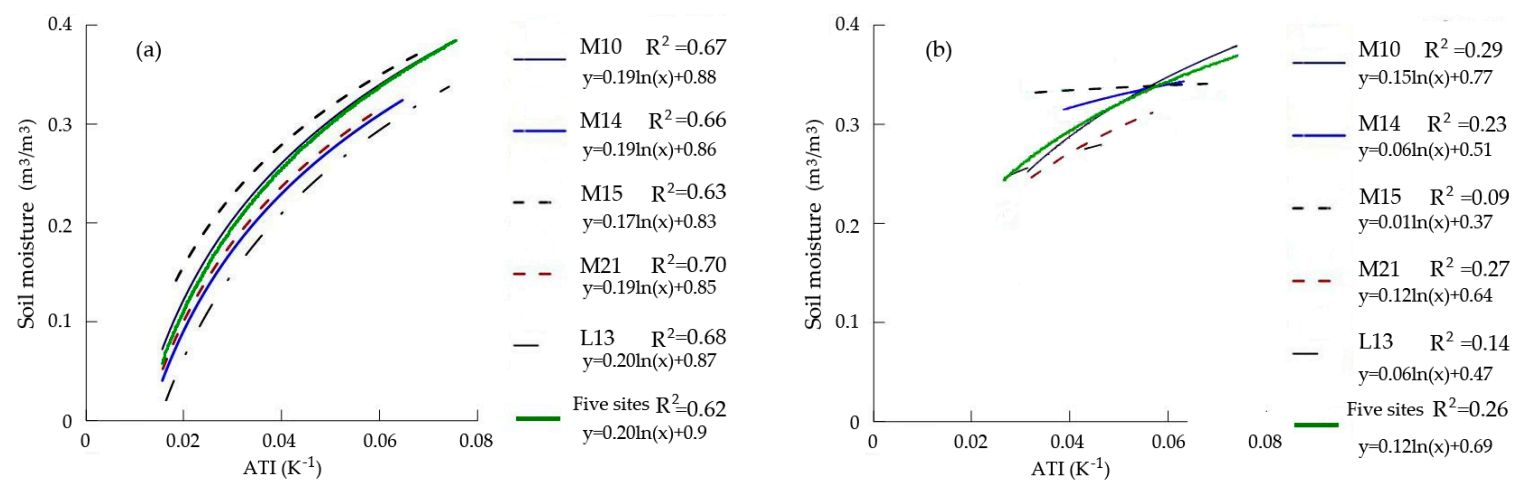

Figure 5. Scatter plots and regression curves of Equation (6) at the five sites of TP-SMTMN under the conditions with (a) NDVI lower than 0.4; and (b) NDVI higher than 0.4.

In general, the linear logarithmic model is robust and can be used to downscale soil moisture together with ATI under the condition when NDVI is lower than 0.4.

\subsection{Downscaling Soil Moisture to 1-km Spatial Resolution}

The algorithm is applied to the study area where the NDVI is lower than 0.4 from 1 January 2012 to 31 December 2012. The time series of confidence level of Equation (7) with FY-3B soil moisture and ATI is shown in Figure 6 for clear-sky days in 2012.

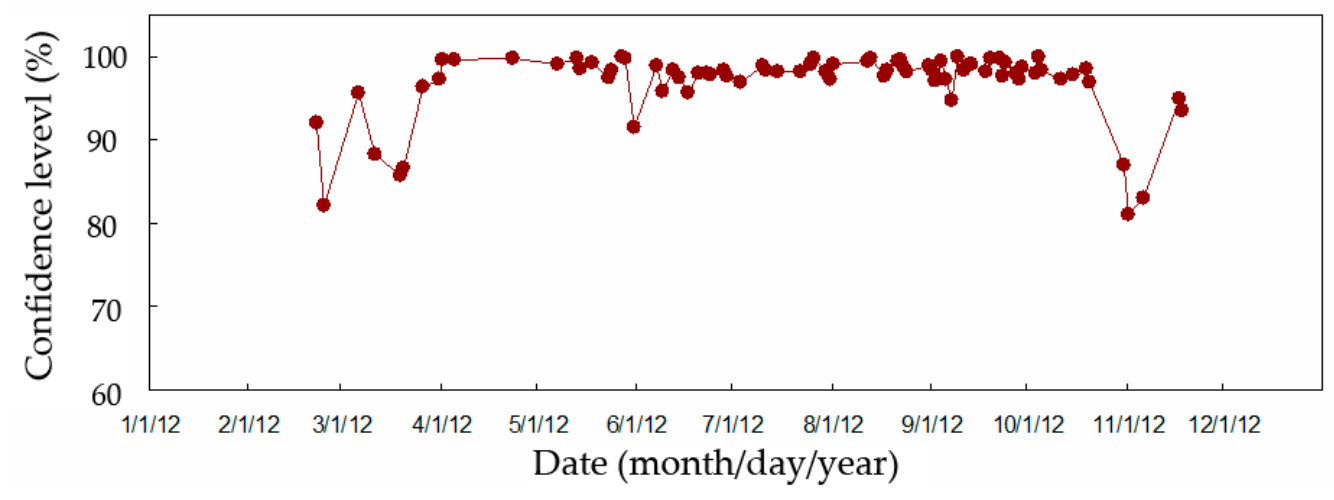

Figure 6. The time series of confidence level of regression between FY-3B soil moisture and ATI using Equation (7) for the period of 2012.

The confidence level is in general higher than $95 \%$ on most days. Low confidence level is found in the frozen season (February, March, October, November), which might be due to the retrieval uncertainties of FY-3B soil moisture product in these season as mentioned in Section 4.1. In general, a higher confidence level of regression between FY-3B soil moisture and ATI using Equation (7) to downscale the FY-3B soil moisture can be achieved in the unfrozen season.

Figure 7 shows the example of downscaled soil moisture in the southeast of the study area at $1 \mathrm{~km}$ on 25 May and 13 September of 2012. The date of 25 May of 2012 was before the monsoon season with drier land surface, whereas date of 13 September of 2012 was after the monsoon season with 
wetter land surface. The original FY-3B 25-km soil moisture products are also shown in Figure 7 to assess the spatial distribution of the downscaled soil moisture.

(a)

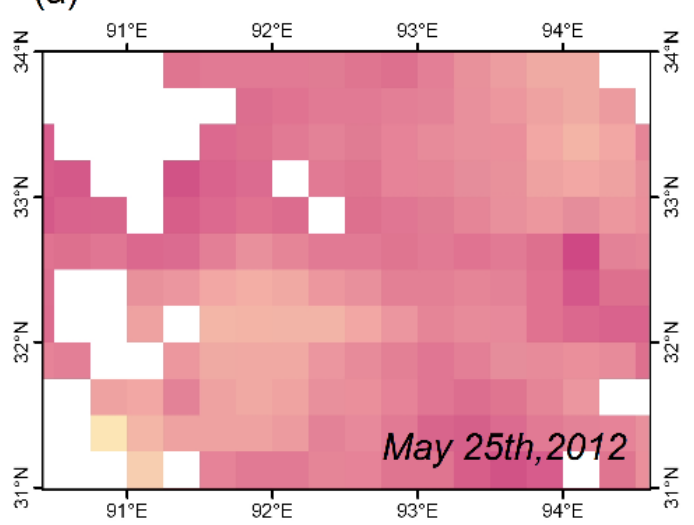

(c)

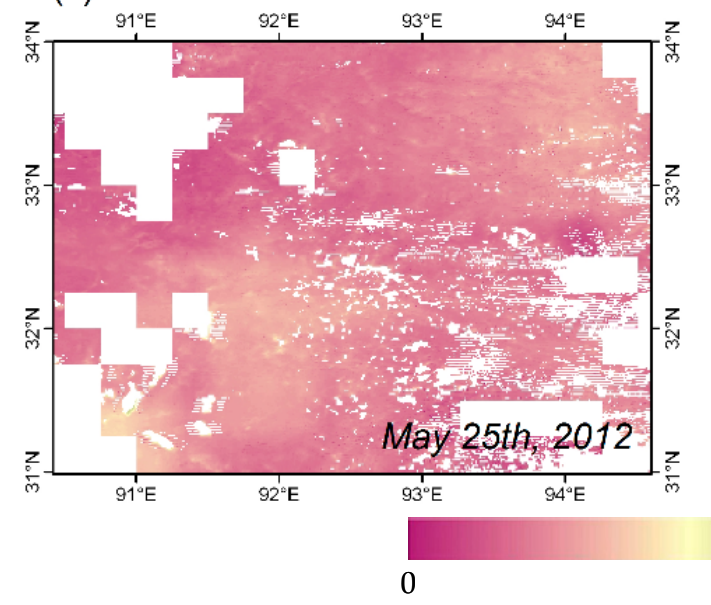

(b)

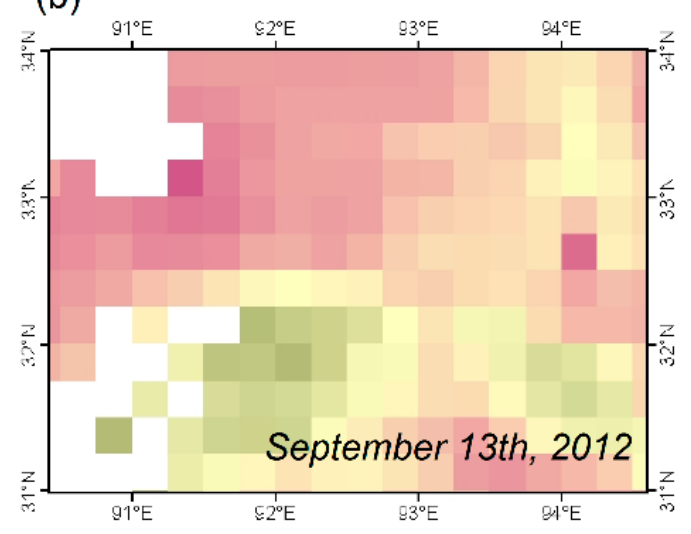

(d)

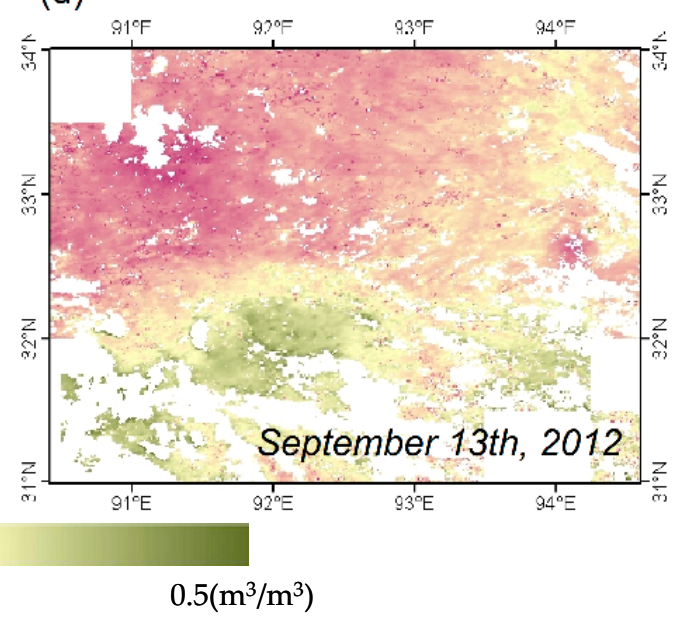

Figure 7. FY-3B soil moisture at 25-km spatial resolution and downscaled soil moisture at 1-km spatial resolution in Naqu area on the Tibetan Plateau on (a,b) 25 May 2012; and (c,d) 13 September 2012.

Due to cloud effect on ATI, the effective area of downscaled soil moisture at 1-km spatial resolution is less than those in the original FY-3B soil moisture product, especially on 13 September of 2012 (Figure $8 \mathrm{~b}$ ). The spatial pattern of the soil moisture at 1-km spatial resolution is similar to that at 25-km spatial resolution over Naqu area. Soil moisture showed higher values on 13 September than on 25 May in 2012, especially in the southwest of the area.

Figure 8 shows the histograms of soil moisture over the area on the two days mentioned above. The histograms of the soil moisture at $1-\mathrm{km}$ spatial resolution is similar to that at $25-\mathrm{km}$ spatial resolution on the two days. The spatially averaged values of soil moisture at $1-\mathrm{km}$ and $25-\mathrm{km}$ spatial resolutions are $0.121 \mathrm{~m}^{3} / \mathrm{m}^{3}$ and $0.115 \mathrm{~m}^{3} / \mathrm{m}^{3}$ on 25 May of 2012. Soil surface is wetter on 13 September of 2012 with averaged values of $0.202 \mathrm{~m}^{3} / \mathrm{m}^{3}$ and $0.199 \mathrm{~m}^{3} / \mathrm{m}^{3}$ at $25-\mathrm{km}$ and $1-\mathrm{km}$ spatial resolutions respectively. Compared with soil moisture at $25-\mathrm{km}$ resolution over the area, the range of soil moisture at $1-\mathrm{km}$ spatial resolution is wider and standard deviation of soil moisture is also larger, although their averaged values were close to each other. This is caused by the increased number of pixels in the downscaled soil moisture so that the values of downscaled soil moisture are more dispersed. The downscaled 1-km soil moisture is evaluated by comparing with the ground measurements of soil moisture at the soil depth of $5 \mathrm{~cm}$ at the five ground sites (see description in Section 4.2) where the land surface are all considered to be homogeneous. Since ATI is more applicable to soil moisture 
monitoring for the conditions when NDVI lower than 0.4, the comparison is only done under this condition. It is observed that the ground measurements of soil moisture ranged from $0.08 \mathrm{~m}^{3} / \mathrm{m}^{3}$ in winter to $0.38 \mathrm{~m}^{3} / \mathrm{m}^{3}$ in summer in 2012 at the site M10. The range of the ground measurements of soil moisture is similar at sites M14 and M21 varying from 0.06 to $0.36 \mathrm{~m}^{3} / \mathrm{m}^{3}$. The range of the soil moisture at site M15 is found ranging between $0.13 \mathrm{~m}^{3} / \mathrm{m}^{3}$ and $0.35 \mathrm{~m}^{3} / \mathrm{m}^{3}$. The soil is relatively drier at site L13 with a range of soil moisture from $0.03 \mathrm{~m}^{3} / \mathrm{m}^{3}$ to $0.31 \mathrm{~m}^{3} / \mathrm{m}^{3}$. The five sites are located in five different pixels, the downscaled 1-km soil moisture from each of the five site-pixels were compared with the ground measurements of soil moisture at each site (Figure 9).
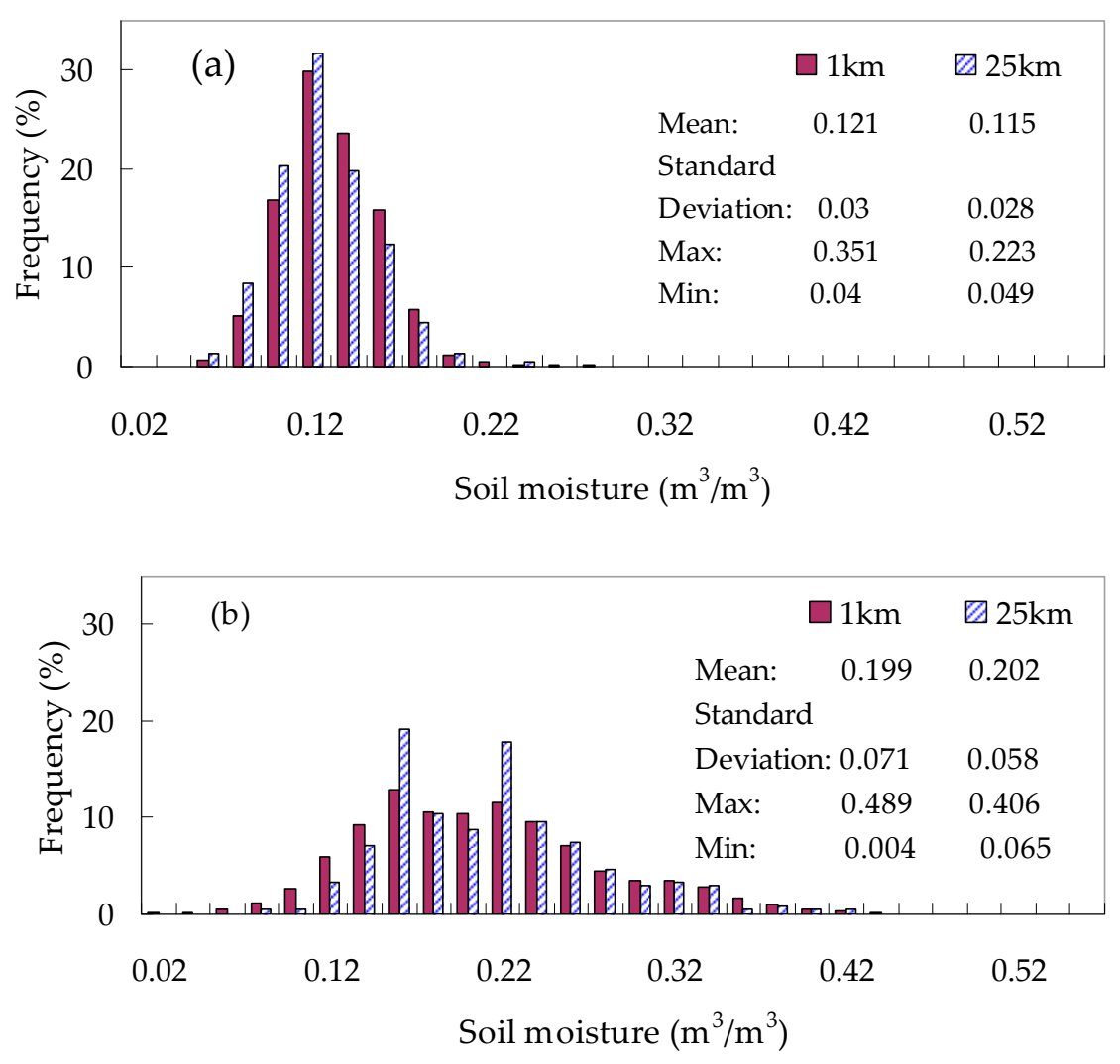

Figure 8. Histograms of soil moisture at $1-\mathrm{km}$ and $25-\mathrm{km}$ spatial resolutions respectively over Naqu area on the Tibetan Plateau on (a) 25 May; and (b) 13 September 2012.

Figure 9 presents the time series of downscaled 1-km soil moisture, together with the in situ measurements at the five sites for 2012. Figure 10 is the scatter plot of downscaled soil moisture and ground based moisture at the five sites. The downscaled soil moisture is higher from the beginning of May to the end of September in 2012, and lower in the winter of 2012 for the five sites. The trends of downscaled soil moisture are similar to the trends of ground measurements in this period at the five sites. However, soil moisture is underestimated from March to May at all sites except at L13, which might be partly due to the underestimation of FY-3B soil moisture during this period (see analysis in Section 4.1) in conjunction with the mismatch in spatial scales between the site and 1-km pixel. The mismatch in scales in ground measurements and pixels of satellite observations is often an issue in particular for the case when land surface condition in a pixel is heterogeneous. The exceptional case is for site L13 (Figure 9e), where the downscaled soil moisture showed rather good agreement with the in-situ measurements. The location of site L13 is far away from the other sites and was drier than the other sites in 2012. The drier conditions in the pixel where site L13 located implies that the condition at site L13 were probably more homogeneous than the other sites during this period, especially in March. In autumn season, the downscaled soil moisture is underestimated at site M15. Compared with the 
other four sites, the elevation of site M15 is the highest (4747 m). The higher elevation would cause soil to become frozen earlier, and the values of ATI were lower in the frozen conditions. This might have caused the downscaled soil moisture lower than ground measurements.
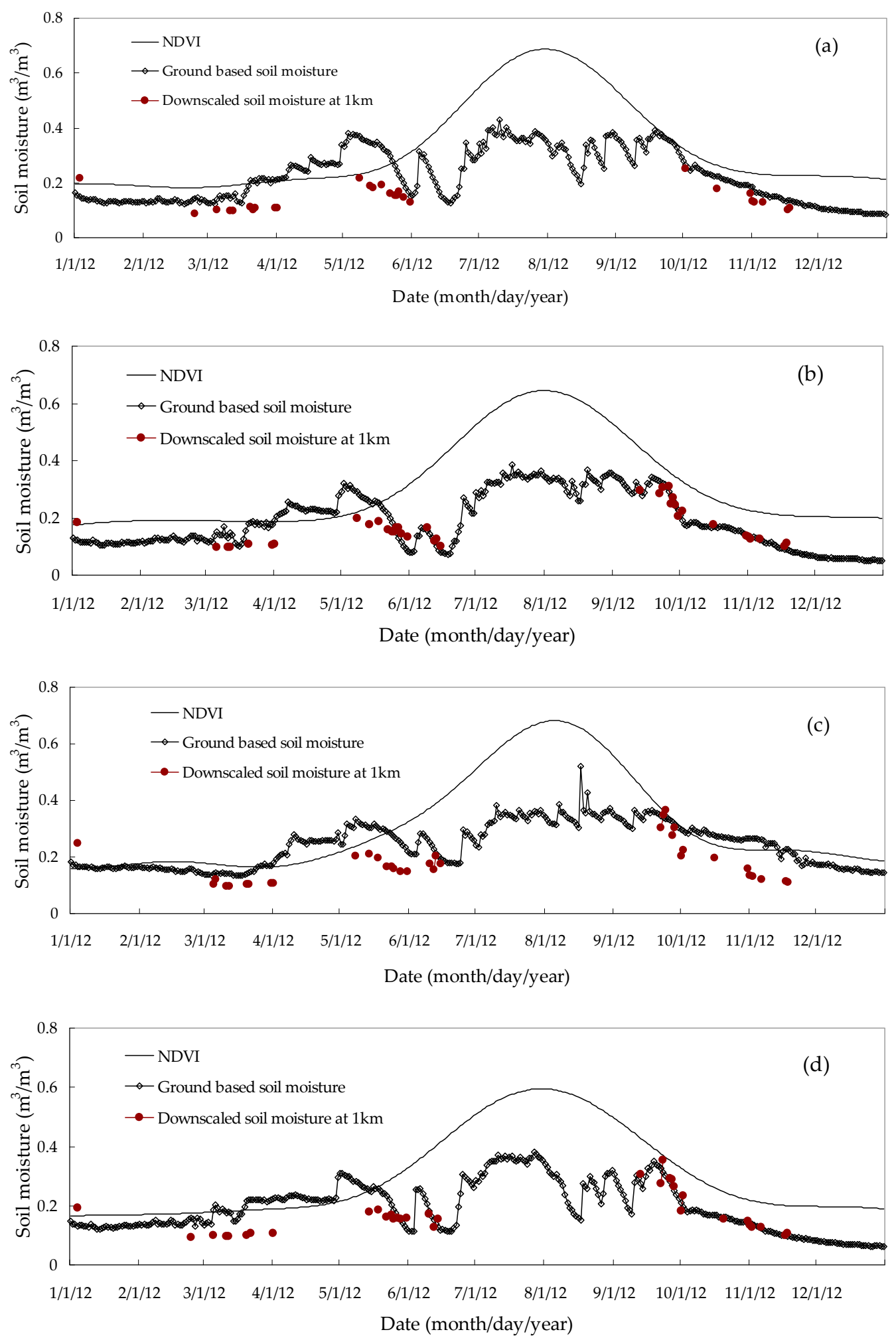

Figure 9. Cont. 


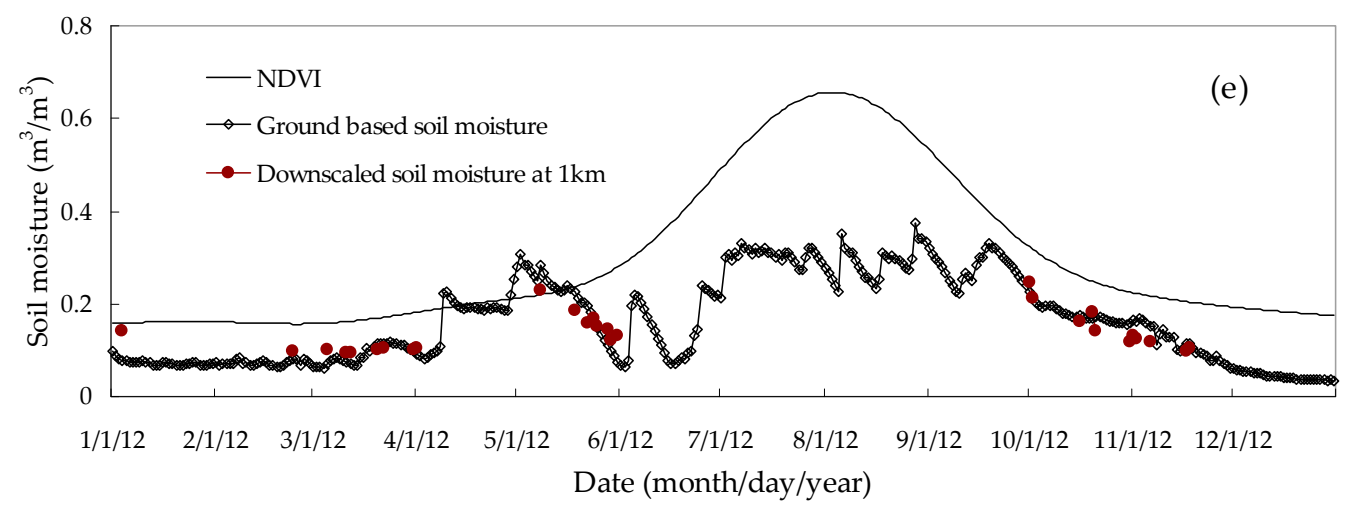

Figure 9. Time series of downscaled soil moisture in comparison with ground measurements at sites (a) M10; (b) M14; (c) M15; (d) M21; and (e) L13 of the TP-SMTMN in Naqu on the Tibetan Plateau in 2012.

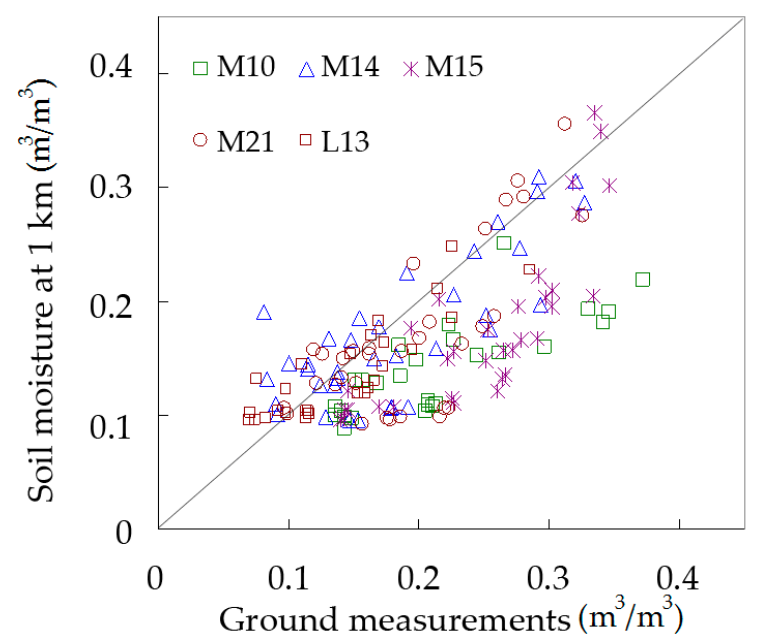

Figure 10. Scatter plot of downscaled soil moisture and ground measurements for the condition of NDVI smaller than 0.4 at the five sites of the TP-SMTMN in Naqu on the Tibetan Plateau in 2012.

Table 1 shows the $R^{2}$, RMSE and the Nash Sutcliffe Coefficient of Efficiency (NSCE) between the downscaled soil moisture at 1-km resolution and the in-situ measurements at the five sites of TP-SMTMN in unfrozen seasons when NDVI values were smaller than 0.4. In the unfrozen season, the values of the $R^{2}$ at the five sites are higher than 0.4 with RMSE smaller than $0.11 \mathrm{~m}^{3} / \mathrm{m}^{3}$, and NSCE is higher than 0.85 . The $R^{2}$ is highest (0.67) at site L13 in unfrozen season with RMSE $0.043 \mathrm{~m}^{3} / \mathrm{m}^{3}$. For the five sites as a whole, the $R^{2}$ is 0.54 , RMSE is $0.063 \mathrm{~m}^{3} / \mathrm{m}^{3}$ and NSCE is 0.95 .

Table 1. The $R^{2}$, RMSE and the NSCE between the downscaled soil moisture and the in-situ measurements at the five sites of TP-SMTMN on the Tibetan Plateau for conditions of NDVI smaller than 0.4 in the unfrozen season of 2012.

\begin{tabular}{cccc}
\hline Site & $\boldsymbol{R}^{\mathbf{2}}$ & RMSE $\left(\mathbf{m}^{\mathbf{3}} / \mathbf{m}^{\mathbf{3}}\right)$ & NSE \\
\hline M10 & 0.45 & 0.102 & 0.89 \\
M14 & 0.60 & 0.047 & 0.97 \\
M15 & 0.55 & 0.089 & 0.88 \\
M21 & 0.64 & 0.042 & 0.87 \\
L13 & 0.67 & 0.043 & 0.92 \\
5 sites & 0.54 & 0.063 & 0.95 \\
\hline
\end{tabular}


Because the Advanced Microwave Scanning Radiometer-Earth Observing System onboard Aqua (Aqua/AMSR-E) and the FY-3B/MWSI have similar sensor specifications, and the required accuracy for soil moisture retrieval by AMSR-E is designed as RMSE lower than $0.06 \mathrm{~m}^{3} / \mathrm{m}^{3}$, we consider the acceptable accuracy for FY-3B soil moisture product and the downscaled soil moisture at 1-km resolution is the same, i.e., with RMSE lower than $0.06 \mathrm{~m}^{3} / \mathrm{m}^{3}$. The average of RMSE of the downscaled FY-3B soil moisture over all sites in 2012 is larger than $0.06 \mathrm{~m}^{3} / \mathrm{m}^{3}$ in unfrozen season of 2012, partly attributed to poorer accuracy in the original FY-3B soil moisture product at low spatial resolution.

In general, the trends of the downscaled soil moisture are similar to the ground measurements under the conditions when NDVI values was smaller than 0.4. Errors in the FY-3B soil moisture product itself could be one of the factors leading to the uncertainties in the downscaled soil moisture. In addition, various land cover types and geological properties in the region have an impact on the relationship between ATI and soil moisture. As a conclusion, the method can generally be applied under conditions with bare soil surface or sparsely vegetated surface, i.e., NDVI smaller than 0.4, as shown in the current study.

\section{Conclusions}

This study presented a method of downscaling the FY-3B 25-km soil moisture product based on the relationship between soil moisture and ATI by using satellite data from optical/thermal bands at high spatial resolution $(1 \mathrm{~km})$. The proposed method assumes that the relationship between soil moisture and ATI is the same but the parameters of the model are different at different spatial scales. ATI was derived from MODIS 1-km spatial resolution LST and albedo data, and soil moisture of FY-3B $25-\mathrm{km}$ product was downscaled to 1-km spatial resolution. It is also assumed that the relationship and coefficients between soil moisture and ATI are the same in the whole study area at the same scale (i.e., spatial resolution). The algorithm is more applicable under conditions with bare surface or surface sparsely covered by vegetation. The method was applied to the Naqu area on the Tibetan Plateau of China. The downscaled 1-km soil moisture was compared with the ground measurements at five ground sites of TP-SMTMN in Naqu on the Tibetan Plateau. The results show that the determinant coefficient $R^{2}$ is higher than 0.4 , RMSE is smaller than $0.11 \mathrm{~m}^{3} / \mathrm{m}^{3}$ and NSCE is higher than 0.85 for unfrozen seasons of 2012. We consider the acceptable accuracy for FY-3B 25-km soil moisture product and the downscaled 1-km soil moisture to be the same as that of AMSR-E soil moisture retrieval, i.e., RMSE lower than $0.06 \mathrm{~m}^{3} / \mathrm{m}^{3}$. The results show that the RMSE of the downscaled FY-3B soil moisture is higher than $0.06 \mathrm{~m}^{3} / \mathrm{m}^{3}$ in unfrozen season. The uncertainties in FY-3B soil moisture at its original low spatial resolution could be one of the important factors that cause the bias in the downscaled soil moisture.

There are several factors that may have influence on the downscaled results. Accuracy of the FY-3B 25-km soil moisture product is important and it determines the reliability of the coefficients of regression between soil moisture and ATI. In addition, the proposed method is more applicable to areas with NDVI values smaller than 0.4 . In the dense vegetation covered area, the observations from optical and thermal infrared bands cannot get the information of the soil under the dense vegetation but the information of the vegetation above the soil, whereas the vegetation conditions reflect more the root zone soil water content other than surface soil moisture. Therefore, the proposed method of downscaling soil moisture with ATI might not be suitable for the conditions with dense vegetation cover. Passive microwave signals can penetrate the vegetation canopy and should be considered in the future for the monitoring of soil surface moisture under denser vegetation cover conditions. For instance, further studies can be focused on using high resolution SAR data to downscale soil moisture over denser vegetation covered areas.

Acknowledgments: This work was jointly supported by the National Key Basic Research Program of China (Grant No. 2015CB953702), National Natural Science Foundation of China (NSFC) (Grant No. 91425303) and Initial Scientific Research Fund in Anhui university of science \& technology (the project serial number: ZY528). 
Author Contributions: Chengyun Song conducted the primary data analysis and drafted the manuscript. Li Jia advised on and contributed to the supervision of the work and significant editing of the manuscript.

Conflicts of Interest: The authors declare no conflict of interest.

\section{Appendix A}

In Section 2, the daily LST amplitude A in Equation (2) can be calculated with the following equation:

$$
\frac{A}{2}=\frac{n \sum_{i=1}^{n} \cos \left(\omega t_{i}-\psi\right) T_{i}-\sum_{i=1}^{n} \cos \left(\omega t_{i}-\psi\right) \sum_{i=1}^{n} T_{i}}{n \sum_{i=1}^{n} \cos ^{2}\left(\omega t_{i}-\psi\right)-\left(\sum_{i=1}^{n} \cos \left(\omega t_{i}-\psi\right)\right)^{2}}
$$

where $T_{i}$ is the LST at time $t_{i}[K], \omega$ is the angular velocity of rotation of the Earth $[\mathrm{rad} / \mathrm{s}], \psi$ is the phase angle [ $\mathrm{rad}]$ and given as:

$$
\begin{gathered}
\psi=\arctan (\xi)+\pi \\
\xi=\frac{\left(T_{1}-T_{3}\right)\left(\cos \left(\omega t_{2}\right)-\cos \left(\omega t_{4}\right)\right)-\left(T_{2}-T_{4}\right)\left(\cos \left(\omega t_{1}\right)-\cos \left(\omega t_{3}\right)\right)}{\left(T_{2}-T_{4}\right)\left(\sin \left(\omega t_{1}\right)-\sin \left(\omega t_{3}\right)\right)-\left(T_{1}-T_{3}\right)\left(\sin \left(\omega t_{2}\right)-\sin \left(\omega t_{4}\right)\right)}
\end{gathered}
$$

Four observations of LST in one day are needed in Equation (A3). The influence of clouds makes it difficult to obtain four observations of LST every day from MODIS, Harmonic Analysis of Time Series (HANTS) are used to obtain $\psi$ of every day [31,32].

The parameter $\mathrm{C}$ in Equation (2) can be calculated with the following equations:

$$
\begin{gathered}
C=\sin \phi \sin \delta\left(1-\tan ^{2} \phi\right)^{1 / 2}+\cos \phi \cos \delta \arccos (-\tan \phi \tan \delta) \\
\delta=0.006918-0.399912 \cos (\Gamma)+0.070257 \sin (\Gamma) \\
-0.006758 \cos (2 \Gamma)+0.000907 \sin (2 \Gamma) \\
-0.002697 \cos (3 \Gamma)+0.00148 \sin (3 \Gamma) \\
\Gamma=\frac{2 \pi\left(n_{d}-1\right)}{365.25}
\end{gathered}
$$

where $\varphi$ is the latitude $[\mathrm{rad}], \delta$ is the solar declination $[\mathrm{rad}]$, and $\mathrm{n}_{\mathrm{d}}$ is the day of the year [-].

\section{References}

1. Bolten, J.D.; Crow, W.T.; Zhan, X.; Jackson, T.J.; Reynolds, C.A. Evaluating the utility of remotely sensed soil moisture retrievals for operational agricultural drought monitoring. IEEE J. Sel. Top. Appl. Earth Observ. Remote Sens. 2010, 3, 57-66. [CrossRef]

2. Seneviratne, S.I.; Corti, T.; Davin, E.L.; Hirschi, M.; Jaeger, E.B.; Lehner, I.; Orlowsky, B.; Teuling, A.J. Investigating soil moisture-climate interactions in a changing climate: A review. Earth-Sci. Rev. 2010, 99, 125-161. [CrossRef]

3. Njoku, E.G.; Entekhabi, D. Passive microwave remote sensing of soil moisture. J. Hydrol. 1996, 184, 101-129. [CrossRef]

4. Schmugge, T.J.; Kustas, W.P.; Ritchie, J.C.; Jackson, T.J.; Rango, A. Remote sensing in hydrology. Adv. Resour. 2002, 25, 1367-1385. [CrossRef]

5. Shi, J.C.; Jiang, L.M.; Zhang, L.X.; Chen, K.S.; Wigneron, J.P.; Chanzy, A.; Jackson, T.J. Physically based estimation of bare-surface soil moisture with the passive radiometers. IEEE Trans. Geosci. Remote Sens. 2006, 44, 3145-3153. [CrossRef]

6. Kerr, Y.H.; Secherre, F.; Lastenet, J.; Wigneron, J.P. SMOS: Analysis of perturbing effects over land surfaces. In Proceedings of the IGARSS 2003: IEEE International Geoscience and Remote Sensing Symposium, Toulouse, France, 21-25 July 2003; pp. 908-910.

7. Njoku, E.G.; Jackson, T.J.; Lakshmi, V.; Chan, T.K.; Nghiem, S.V. Soil moisture retrieval from AMSR-E. IEEE Trans. Geosci. Remote Sens. 2003, 41, 215-229. [CrossRef] 
8. Entekhabi, D.; Njoku, E.G.; O’Neill, P.E.; Kellogg, K.H.; Crow, W.T.; Edelstein, W.N.; Entin, J.K.; Goodman, S.D.; Jackson, T.J.; Johnson, J.; et al. The soil moisture active passive (SMAP) mission. IEEE Proc. 2010, 98, 704-716. [CrossRef]

9. Liu, Y.Y.; Parinussa, R.M.; Dorigo, W.A.; Wagner, W.; Dijk, A.I.J.M.; McCabe, M.F.; Evans, J.P. Developing an improved soil moisture dataset by blending passive and active microwave satellite-based retrievals. Hydrol. Earth Syst. Sci. 2011, 15, 425-436. [CrossRef]

10. Yin, J.; Zhan, X.; Zheng, Y.; Liu, J.; Fang, L.; Hain, C.R. Enhancing model skill by assimilating SMOPS blended soil moisture product into noah land surface model. J. Hydrometeorol. 2015, 16, 917-931. [CrossRef]

11. Carlson, T. An overview of the "triangle method" for estimating surface evapotranspiration and soil moisture from satellite imagery. Sensors 2007, 7, 1612-1629. [CrossRef]

12. Crow, W.T.; Wood, E.F.; Dubayah, R. Potential for downscaling soil moisture maps derived from spaceborne imaging radar data. J. Geophys. Res. Atmos. 2000, 105, 2203-2212. [CrossRef]

13. Piles, M.; Camps, A.; Vall-Llossera, M.; Corbella, I.; Panciera, R.; Rudiger, C.; Kerr, Y.H.; Walker, J. Downscaling SMOS-derived soil moisture using MODIS visible/infrared data. IEEE Trans. Geosci. Remote Sens. 2011, 49, 3156-3166. [CrossRef]

14. Chauhan, N.; Miller, S.; Ardanuy, P. Spaceborne soil moisture estimation at high resolution: A microwave-optical/IR synergistic approach. Int. J. Remote Sens. 2003, 24, 4599-4622. [CrossRef]

15. Piles, M.; Entekhabi, D.; Camps, A. A Change detection algorithm for retrieving high-resolution soil moisture from SMAP radar and radiometer observations. IEEE Trans. Geosci. Remote Sens. 2009, 47, 4125-4131. [CrossRef]

16. Song, C.; Jia, L.; Menenti, M. Retrieving high-resolution surface soil moisture by downscaling AMSR-E brightness temperature using MODIS LST and NDVI Data. IEEE J. Sel. Top. Appl. Earth Observ. Remote Sens. 2014, 7, 935-942. [CrossRef]

17. Merlin, O.; Walker, J.P.; Chehbouni, A.; Kerr, Y. Towards deterministic downscaling of SMOS soil moisture using MODIS derived soil evaporative efficiency. Remote Sens. Environ. 2008, 112, 3935-3946. [CrossRef]

18. Wagner, W.; Pathe, C.; Doubkova, M.; Sabel, D.; Bartsch, A.; Hasenauer, S.; Bloschl, G.; Scipal, K.; Martinez-Fernandez, J.; Low, A. Temporal stability of soil moisture and radar backscatter observed by the advanced Synthetic Aperture Radar (ASAR). Sensors 2008, 8, 1174-1197. [CrossRef]

19. Minacapilli, M.; Iovino, M.; Blanda, F. High resolution remote estimation of soil surface water content by a thermal inertia approach. J. Hydrol. 2009, 379, 229-238. [CrossRef]

20. Xue, Y.; Cracknell, A. Advanced thermal inertia modelling. Remote Sens. 1995, 16, 431-446. [CrossRef]

21. Cai, G.; Xue, Y.; Hu, Y.; Wang, Y.; Guo, J.; Luo, Y.; Wu, C.; Zhong, S.; Qi, S. Soil moisture retrieval from MODIS data in Northern China Plain using thermal inertia model. Int. J. Remote Sens. 2007, 28, 3567-3581. [CrossRef]

22. Verstraeten, W.W.; Veroustraete, F.; van der Sande, C.J.; Grootaers, I.; Feyen, J. Soil moisture retrieval using thermal inertia, determined with visible and thermal spaceborne data, validated for European forests. Remote Sens. Environ. 2006, 101, 299-314. [CrossRef]

23. Doninck, J.V.; Peters, J.; Baets, B.D.; Clercq, E.M.; Ducheyne, E.; Verhoest, N.E.C. The potential of multitemporal Aqua and Terra MODIS Apparent Thermal Inertia as a soil moisture indicator. Int. J. Appl. Earth Observ. Geoinf. 2011, 13, 934-941. [CrossRef]

24. Notarnicola, C.; Lewińska, K.E.; Temimi, M.; Zebisch, M. Application of the Apparent Thermal Inertia concept for soil moisture estimation in agricultural areas. In Thermal Infrared Remote Sensing: Sensors, Methods, Applications, Remote Sensing and Digital Image Processing; Springer: Houten, The Netherlands, 2013; pp. 331-346.

25. Price, J.C. On the analysis of thermal infrared imagery: The limited utility of apparent thermal inertia. Remote Sens. Environ. 1985, 18, 59-73. [CrossRef]

26. Veroustraete, F.; Li, Q.; Verstraeten, W.W.; Chen, X.; Bao, A.; Dong, Q.; Liu, T.; Willems, P. Soil moisture content retrieval based on Apparent Thermal Inertia for Xinjiang province in China. Int. J. Remote Sens. 2012, 33, 3870-3885. [CrossRef]

27. Qin, J.; Yang, K.; Lu, N.; Chen, Y.; Zhao, L.; Han, M. Spatial upscaling of in-situ soil moisture measurements based on MODIS-derived apparent thermal inertia. Remote Sens. Environ. 2013, 138, 1-9. [CrossRef]

28. Fengyun Satellite Data Center. Available online: http://satellite.nsmc.org.cn/portalsite/default.aspx (accessed on 10 March 2014). 
29. National Snow and Ice Data Center (NSIDC). Available online: http://nsidc.org/ (accessed on 10 March 2014).

30. Yang, K.; Qin, J.; Zhao, L.; Chen, Y.; Tang, W.; Han, M.; Chen, Z.; Lv, N.; Ding, B.; Wu, H.; et al. A multi-scale soil moisture and freeze-thaw monitoring network on the third pole. Bull. Am. Meteorol. Soc. 2013, 94, 1907-1916. [CrossRef]

31. Roerink, G.; Menenti, M.; Verhoef, W. Reconstructing cloud free NDVI composites using Fourier analysis of time series. Int. J. Remote Sens. 2000, 21, 1911-1917. [CrossRef]

32. Menenti, M.; Azzali, S.; Verhoef, W.; van Swol, R. Mapping agroecological zones and time lag in vegetation growth by means of Fourier analysis of time series of NDVI images. Adv. Space Res. 1993, 13, $233-237$. [CrossRef] article distributed under the terms and conditions of the Creative Commons Attribution (CC-BY) license (http://creativecommons.org/licenses/by/4.0/). 